\title{
Differentiating location- and distance-based processes in memory for time: An ERP study
}

\author{
TIM CURRAN \\ University of Colorado, Boulder, Colorado \\ and \\ WILLIAM J. FRIEDMAN \\ Oberlin College, Oberlin, Ohio
}

\begin{abstract}
Memory for the time of events may benefit from reconstructive, location-based, and distance-based processes, but these processes are difficult to dissociate with behavioral methods. Neuropsychological research has emphasized the contribution of prefrontal brain mechanisms to memory for time but has not clearly differentiated location- from distance-based processing. The present experiment recorded event-related brain potentials (ERPs) while subjects completed two different temporal memory tests, designed to emphasize either location- or distance-based processing. The subjects' reports of locationbased versus distance-based strategies and the reaction time pattern validated our experimental manipulation. Late (800-1,800 msec) frontal ERP effects were related to location-based processing. The results provide support for a two-process theory of memory for time and suggest that frontal memory mechanisms are specifically related to reconstructive, location-based processing.
\end{abstract}

An important property of human memory, and one that has been used as a defining feature of episodic memory (e.g., Wheeler, Stuss, \& Tulving, 1997), is that events seem to belong to particular times in our past. A considerable body of research has been devoted to elucidating the processes underlying humans' memory for when in the past an event occurred (W. J. Friedman, 1993). To understand the findings, it is essential to distinguish between several kinds of processes.

The two most important processes are probably locationbased and distance-based processes (W. J. Friedman, 1993, 1996, 2001). Location-based processes involve relating events to particular time patterns: conventional patterns (e.g., parts of a day or parts of the year), personal patterns (when I was in college), or patterns produced in experiments (Trial Block 1, 2, etc.). There is evidence that adults usually do this by reconstructing when the time of an event must have been, given the general contextual information that is remembered about the event (W. J. Friedman, 1996, 2001). Distance processes involve estimating the amount of time that has elapsed between the event and the present.

The present research was supported by a grant from the McDonnellPew Program in Cognitive Neuroscience, NIMH Grant MH64812, and NSF Grant SBR 98-15791. Thanks to Patricia deWinstanley for suggestions about the experimental design, to P. Carpenter, D. Collins, P. Drocton, A. Patel, M. Polak, C. Ojala, D. Scott, A. Viswanathan, K. Waimey, and C. Westall for research assistance, and to Electrical Geodesics Inc. for technical support. Correspondence concerning this article should be addressed to T. Curran, Department of Psychology, University of Colorado, Campus Box 345, Boulder, CO 80309-0345 (e-mail: tcurran @ psych.colorado.edu).
The psychological processes have not been determined, but it appears that some general property of memories is involved-most likely related to memorial strength or vividness (W. J. Friedman, 1996, 2001).

At present, there is also no evidence on the neuropsychological basis of distance-based processing, but neuropsychological research has suggested that reconstructive, location-based processing may depend on the integrity of the prefrontal cortex. Patients with lesions in the prefrontal cortex are poor at performing laboratory tasks measuring temporal memory or at remembering the times of public events (Butters, Kaszniak, Glisky, Eslinger, \& Schacter, 1994; McAndrews \& Milner, 1991; Milner, Corsi, \& Leonard, 1991; Shimamura, Janowsky, \& Squire, 1990). Functional neuroimaging experiments have similarly related prefrontal activity to memory for the time of events (Cabeza, Anderson, Houle, Mangels, \& Nyberg, 2000; Zorrilla, Aguirre, Zarahn, Cannon, \& D'Esposito, 1996). Evidence suggests that frontal contributions may originate in more general processes that allow reconstruction (Moscovitch, 1995; Shimamura et al., 1990; Wheeler et al., 1997). For example, patients with prefrontal lesions are impaired on a variety of tasks that require the reconstruction of both temporal and nontemporal information (Mangels, Gershberg, Shimamura, \& Knight, 1996; Moscovitch \& Melo, 1997).

Memory for when an event occurred can also be considered a special case of source memory (Johnson, Hashtroudi, \& Lindsay, 1993), and here, too, links to frontal event-related potentials (ERPs) have been demonstrated. For a relatively late and extended period following onset of 
a test item (500-2,000 msec), right frontal ERPs are more positive when subjects recollect the source of a studied item, as compared with conditions lacking source retrieval (reviewed in Allan, Wilding, \& Rugg, 1998; D. Friedman \& Johnson, 2000; Mecklinger, 2000). Many studies have measured late frontal ERP effects in source memory experiments requiring retrieval of nontemporal attributes, such as format (words vs. pictures; Johnson, Kounios, \& Nolde, 1996), speaker's voice (Senkfor \& Van Petten, 1998; Wilding, 1999; Wilding \& Rugg, 1996, 1997b), encoding task (Wilding, 1999), associative pairing (Donaldson \& Rugg, 1998), and spatial location (Van Petten, Senkfor, \& Newberg, 2000). Other recent studies specifically have tested memory for when in the past an event occurred and found similar frontal ERP effects (Tendolkar \& Rugg, 1998; Trott, R. Friedman, Ritter, Fabiani, \& Snodgrass, 1999). Late frontal ERP old/new effects are thought to be related to postretrieval evaluation processes (Allan et al., 1998; Curran, Schacter, Johnson, \& Spinks, 2001; Johnson et al., 1996; Ranganath \& Paller, 2000; Wilding, 1999; Wilding \& Rugg, 1997a, 1997b), and these processes may be important for location-based memory for when an event occurred.

The distinction between location-based and distancebased processes is reminiscent of the difference between recollection and familiarity that has been advocated within dual-process theories of recognition memory (Hintzman \& Curran, 1994; Jacoby, 1991; Mandler, 1980). Indeed, some ERP research has suggested that late frontal ERP old/new effects are related to recollection(e.g., Allan et al., 1998; Curran et al., 2001). Relating frontal activity to both source memory (as was noted above) and recollection is consistent with Jacoby's (1991) process dissociation procedure that assumes source memory to be diagnostic of recollection (Buchner, Erdfelder, Steffens, \& Martensen, 1997; Mulligan \& Hirshman, 1997; Steffens, Buchner, Martensen, \& Erdfelder, 2000; Yu \& Bellezza, 2000). Broadly speaking, we agree with the notion that frontal mechanisms contribute to source recollection. However, a major goal of the present research is to provide a clearer assessment of the conditions likely to engage these frontal mechanisms. In this regard, we believe the distinction between location-based and distance-based processes that has been advanced with regard to memory for time provides a useful framework for delineating these frontal contributions. To anticipate our results, we will show that frontal mechanisms are not equally active in all instances of source memory (or source recollection) but that they are especially involved under conditions that foster reconstructive, location-based processing.

The present research was designed to provide a clearer assessment of the relation between these late frontal ERP effects and location-based memory process, as opposed to distance-based processes. The experiment introduces a new method for studying these two processes by varying (1) the temporal intervals tested, (2) the presence of temporally diagnostic contextual cues, and (3) the retrieval strategies suggested to subjects. First, previous research has shown that distance-based judgments are most accu- rate when the temporal separation between two events is large, relative to their distances from the memory test (W. J. Friedman, 1996), so we compared conditions with differing temporal separations between events. Each subject studied three lists of pictures, spaced over two days (see Table 1). The first list was presented on Day 1. The second and third lists were presented on Day 2. Each subject completed two memory tests on Day 2, in which they were asked to make a three-choice discrimination between new items, items studied at Time 1, and items studied at Time 2. In the day test, Time 1 items were taken from List 1 (Day 1), and Time 2 items were taken from List 2 (Day 2). In the context test, all the studied items were taken from Day 2 (List 2 vs. List 3). Thus, given the ratios of retention intervals, distance-based processing would be more likely in the day test than in the context test. Second, the study context was manipulated so that it was constant for the day test (List 1 and List 2 in the same context; see Table 1) but varied for the context test (List 2 and List 3 in different contexts). Thus, the context test provided temporally diagnostic contextual information that is likely to be used by reconstructive, location-based processes. Third, the subjects were encouraged to use distance-based information in the day test but location-based information in the context test. We predicted that memory-related frontal ERP effects (late frontal positivity) would be stronger in the context than in the day test. This would provide evidence that frontal memory mechanisms are specifically related to locationbased memory processing, and it would provide neurophysiological support for the general supposition that multiple processes are involved in memory for when an event occurred.

\section{METHOD}

\section{Subjects}

Forty right-handed students from Case Western Reserve University participated in two sessions on consecutive days for a total payment of \$25. Data from 18 subjects were discarded for reasons specified in the EEG/ERP Methods section.

\section{Stimuli}

Stimuli were 300 gray-scale line drawings that were taken from a commercially available clipart database (Art Explosion by Nova Development Corp., Calabasas, CA) or from Snodgrass and Vanderwart (Snodgrass \& Vanderwart, 1980). Pictures depicted a variety of objects, animals, people (e.g., football player, nurse, or woman with baby carriage), and scenes. Pictures were approximately $3.2 \mathrm{~cm}$ wide $\times 3.2 \mathrm{~cm}$ high and subtended a visual angle of approximately $3.16^{\circ}$. The pictures were rotated through the six experimental conditions across subjects.

\section{Design and Procedure}

Each subject participated on 2 consecutive days that included three study lists and two test lists. All the variables were manipu-

Table 1

Study Conditions

\begin{tabular}{ccc}
\hline Study List & Day & Context \\
\hline 1 & 1 & 1 \\
2 & 2 & 1 \\
3 & 2 & 2 \\
\hline
\end{tabular}


lated within subjects. The design of the study conditions is summarized in Table 1. On Day 1, the subjects studied a single list of 50 pictures (Study List 1). On Day 2, the subjects studied a list of 100 pictures (Study List 2), followed immediately by a list of 50 pictures (Study List 3). The study list context (specified below) was the same for Study Lists 1 and 2 but different for List 3. The Geodesic Sensor Net was fitted to the subjects after List 3 . The mean time interval between the end of Study List 3 and the beginning of Test List 1 was $34 \mathrm{~min}$ (range, 26-45 $\mathrm{min}$ ).

Each picture was studied for $5 \mathrm{sec}$ with a 1-sec intertrial interval, and the subjects named each picture aloud. The subjects were informed that their memory for the pictures would be tested on the 2nd day of the experiment. Study context was manipulated by varying both encoding task and aspects of the environment in which the pictures were presented. In Environmental Context A, the pictures were presented against a yellow background, on a 17-in. monitor, in a small dark room, while the subject sat on a barstool. In Environmental Context $\mathrm{B}$, the pictures were presented against a red background, on a 21-in. monitor, in a large well-lit room, while the subject sat in a desk chair. Both contexts were separate from the testing context. Contexts A and B were counterbalanced across subjects, so that $\mathrm{A}$ was presented first (Lists 1 and 2) for half the subjects and second (List 3 ) for the other half. In addition, to strengthen the availability of contextual cues, one of two encoding tasks was assigned to each environmental context (counterbalanced across environmental contexts). Each task required the subjects to rate the pictures on a 4point scale by pressing one of four keys. In the liking task, the subjects rated how much they liked the picture (strongly dislike, somewhat dislike, somewhat like, or strongly like). In the frequency task, the subjects rated how frequently they encountered the things or situations represented in the picture (very rarely, somewhat rarely, somewhat often, or very often).

In the day test, the subjects pressed one key for pictures presented on Day 1 (List 1), another key for pictures presented on Day 2 (List 2), and a third key for new pictures. To encourage strength-based processing, the subjects were specifically instructed, "When you complete this test it will often be helpful to just use your intuitive feel for whether an item was seen today or yesterday." In the context test, the subjects pressed one key for pictures presented on the first list of Day 2 (List 2), another key for pictures presented on the second list of Day 2 (List 3), and a third key for new pictures. To encourage location-based processing, the subjects were specifically instructed that it would be helpful to remember the context in which they had studied the pictures. Response keys for studied pictures were assigned to the first two fingers of one hand, and the new response key was assigned to the first finger of the other hand (counterbalanced across subjects). Each test list contained 150 pictures (50 per condition). Test list order was counterbalanced across subjects. A memory strategies questionnaire was completed after each test list.

Test trial timing was synchronized to the $15-\mathrm{msec}$ screen refresh rate. Each test trial began with an open circle (3.2-cm diameter) for a variable duration $(525-1,005 \mathrm{msec})$. The circle was replaced by the test picture for $1,995 \mathrm{msec}$, which in turn was replaced by a central question mark. The question mark remained on the screen until the subject pressed a response key. An open square (3.2-cm sides) appeared after the subject responded and remained visible throughout the 2-sec interstimulus interval. The subjects were instructed to respond as quickly as possible, to remain motionless, and to minimize eye blinks.

The memory strategy questionnaires contained 10 statements describing possible strategies that the subjects might have used for each test (see the Appendix). The subjects rated each strategy on a 7-point scale ranging from never used to used on every picture.

\section{EEG/ERP Methods}

Scalp voltages were collected with a 128-channel Geodesic Sensor Net (Tucker, 1993) connected to an AC-coupled, 128-channel, highinput impedance amplifier (200 M $\Omega$, Net Amps, Electrical Geode- sics Inc., Eugene, OR). Amplified analog voltages (0.1- to $100-\mathrm{Hz}$ bandpass, $-3 \mathrm{~dB}$ ) were digitized at $250 \mathrm{~Hz}$. Individual sensors were adjusted until impedances were less than $50 \mathrm{k} \Omega$.

ERPs were baseline corrected with respect to a $100-\mathrm{msec}$ prestimulus recording interval and were digitally low-pass filtered at $40 \mathrm{~Hz}$. EEG was measured with respect to a vertex reference $(\mathrm{Cz})$, but an average reference transformation was used to minimize the effects of reference site activity and accurately estimate the scalp topography of the measured electrical fields (Bertrand, Perin, \& Pernier, 1985; Curran, Tucker, Kutas, \& Posner, 1993; Dien, 1998; Lehman \& Skrandies, 1985; Picton, Lins, \& Scherg, 1995; Tucker, Liotti, Potts, Russell, \& Posner, 1994). Average reference ERPs are computed for each channel as the voltage difference between that channel and the average of all the channels.

\section{RESULTS}

For the purposes of this brief report, our analyses were limited to the particular conditions, electrode sites, and ERP epochs most relevant to the issues outlined in the introduction. We are primarily interested in late frontal task differences that are not confounded with retention interval. Both tests (day and context) included new pictures and pictures that appeared on Study List 2 (the first list of Day 2), so only the results from these conditions will be presented. No results from List 1 (day only) and List 3 (context only) are presented, because they were not represented in both test tasks. Results from other conditions, locations, and temporal windows will be published elsewhere (Curran \& W. J. Friedman, in press). ${ }^{1}$

\section{Behavioral Results}

The behavioral results and $t$ tests comparing the day and the context tests are presented for each dependent measure in Table 2. False alarm rates were higher for the day than for the context test. Reaction times (RTs) to old pictures were shorter for the day than for the context test.

The memory strategy questionnaire was used to evaluate the use of strength- versus context-based retrieval strategies. Strength-based strategies were probed with Items 4, 7 , and 9; context-based strategies were probed with Items 2 , 5 , and 10 (the other items were fillers). The strategies were analyzed by calculating each subject's mean rating across the strength and the context items separately (bottom rows of Table 2). The results confirmed our prediction that distance-based strategies would be used more in the day test than in the context test, but location-based strategies would be used more in the context test.

Table 2

Behavioral Results

\begin{tabular}{lccl}
\hline \multicolumn{1}{c}{ Measure } & Context & Day & \multicolumn{1}{c}{$t$} \\
\hline Hits & 0.76 & 0.80 & 1.06 \\
False alarms & 0.08 & 0.23 & $6.15^{* *}$ \\
RT (old) & 1,839 & 1,259 & $7.91^{* *}$ \\
RT (new) & 1,292 & 1,390 & 0.70 \\
Strength strategies & 4.41 & 4.91 & $2.15^{*}$ \\
Context strategies & 5.09 & 4.55 & $3.43^{* *}$ \\
\hline
\end{tabular}

Note-RT, reaction time in milliseconds (from accurate trials only). $* p<.05 . \quad * * p<.01$. 


\section{ERP Results}

ERPs were computed from correct trials within each of the four task $\times$ old/new conditions (as in the behavioral analyses, old items were taken only from List 2). Trials were discarded from analyses if they contained eye movements (vertical EOG channel differences greater than $70 \mu \mathrm{V}$ ) or more than $10 \mathrm{bad}$ channels (changing more than $100 \mu \mathrm{V}$ between samples or reaching amplitudes over $200 \mu \mathrm{V})$. ERPs from individual channels that were consistently bad for a given subject were replaced using a spherical interpolation algorithm (Srinivasan, Nunez, Silberstein, Tucker, \& Cadusch, 1996). The median number of excluded channels/subject was $1.00($ mean $=.91$, mode $=1$, range $=0-4$ ). Data from 18 subjects were discarded because 2 failed to follow instructions and 16 did not have sufficient numbers of correct trials in each condition. ${ }^{2}$ For the final 22 subjects included in the analyses, the mean number of acceptable trials per condition per subject was 33 (range $=21-48$ per condition per subject).

ERPs were analyzed within six frontal channel clusters (three per hemisphere) that included the Fp1/Fp2, F7/F8, and F3/F4 locations of the International 10-20 system (Jasper, 1958; see Figure 1 for locations). ERPs from individual channels were averaged within each region, and the resulting grand averages are plotted in Figure 2 (labeled Fp1+/Fp2+, F7+/F8+, and F3+/F4+). The dependent measure was mean amplitude between 800 and $1,800 \mathrm{msec}$. The temporal window was selected to include the late frontal effects of interest but to exclude earlier ERP old/new effects that typically last between 300 and 800 msec (e.g., Allan et al., 1998; Curran, 2000; D. Friedman \& Johnson, 2000; Mecklinger, 2000).

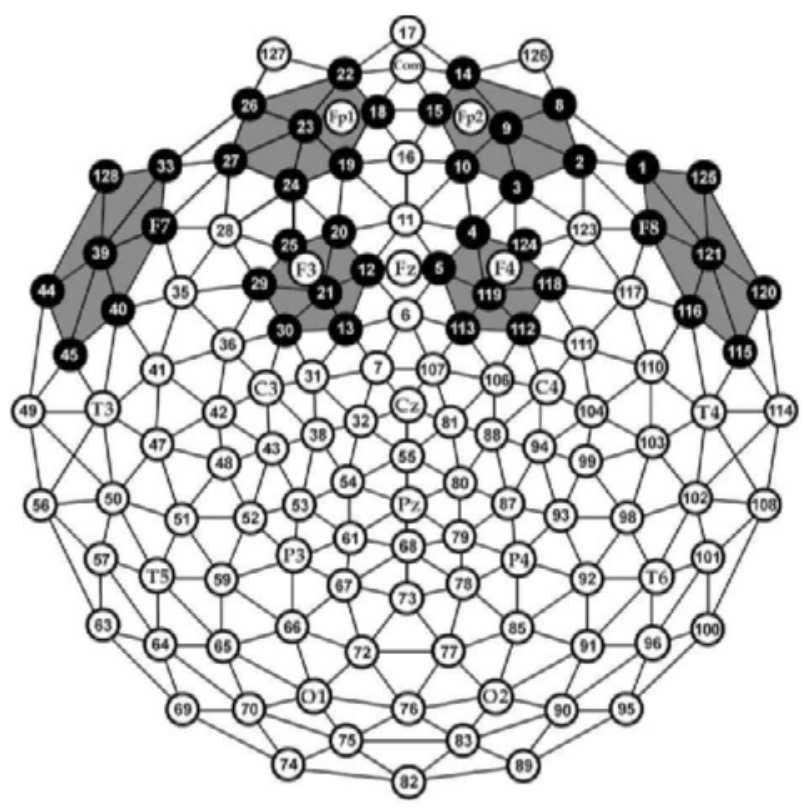

Figure 1. Approximate channel locations on the Geodesic Sensor Net. Locations from the International 10-20 system are shown for reference. The six dark clusters depict the locations used for analyses, which are named according to the nearest 10-20 equivalent locations: Fp1+/Fp2+, F7+/F8+, and F3+/F4+.
Mean amplitudes were analyzed in a task $\times$ old/new $\times$ hemisphere $X$ region repeated measures analysis of variance (ANOVA). Main effects for both task [context $>$ day; $\left.F(1,21)=6.12, M S_{\mathrm{e}}=9.51, p<.05\right]$ and old $/$ new [old $>$ new; $\left.F(1,21)=16.70, M S_{\mathrm{e}}=4.06, p<.001\right]$ were significant. Old/new interacted with hemisphere such that old/new effects were primarily right lateralized $[F(1,21)=$ $12.16, M S_{\mathrm{e}}=2.30, p<.01 ;$ see Figure 3]. The task $\times$ old $/$ new interaction suggested that task differences were larger for old than for new items $\left[F(1,21)=9.08, M S_{\mathrm{e}}=2.55\right.$, $p<.01]$. From another perspective, the interaction indicates that the frontal differentiation between old and new pictures (ERP old/new differences) was greater for the context test (mean amplitudes: old $=2.82 \mu \mathrm{V}$, new $=1.72 \mu \mathrm{V}$ ) than for the day test (old $=1.78 \mu \mathrm{V}$, new $=1.48 \mu \mathrm{V}$ ).

Follow-up ANOVAs were conducted for old and new items separately. The task effect was significant for old items $\left[F(1,21)=10.94, M S_{\mathrm{e}}=7.07, p<.01\right]$ but did not significantly interact with hemisphere $[F(1,21)=2.02$, $\left.M S_{\mathrm{e}}=3.72\right]$. The task $\times$ hemisphere $\times$ region interaction was significant for new items $\left[F(1,21)=5.19, M S_{\mathrm{e}}=\right.$ $0.62, p<.05$; corrected for sphericity violations, epsilon $=$ .973; Geisser \& Greenhouse, 1958]. New items showed task differences (context $>$ day) only over the right Fp2+ region.

RT was much longer for old items in the context than in the day tasks - as would be expected if the context task required more reconstructive processing. Our results suggest that longer RTs and increased frontal ERP activity are both related to reconstructive processing, but it is also conceivable that ERP differences are merely an artifact of the RT differences. We doubt that the ERP task differences are entirely attributable to RT differences, because substantial RT task differences were also observed in an unpublished experiment that was similar to the present experiment yet failed to yield task-related ERP effects, because a weaker context manipulation was used.

In summary, frontal amplitudes were more positive for items tested in the context condition than in the day condition. These differences were larger and more widespread for old than for new items.

\section{DISCUSSION}

The behavioral results are consistent with the hypothesized differences between location-based processing in the context task and distance-based processing in the day task (W. J. Friedman, 1993, 1996, 2001). First, the subjects reported more frequent use of location-based memory strategies in the context test and more use of distancebased memory strategies in the day test. Second, the longer RTs shown for old pictures in the context than in the day tests are also consistent with greater use of reconstructive, location-based processes in the former test, because reconstructive processes should take longer than a direct assessment of distance/strength. The behavioral results are novel in their own right, because we know of no other laboratory experiments that have dissociated distance-based from location-based processes with strategy reports or RT 


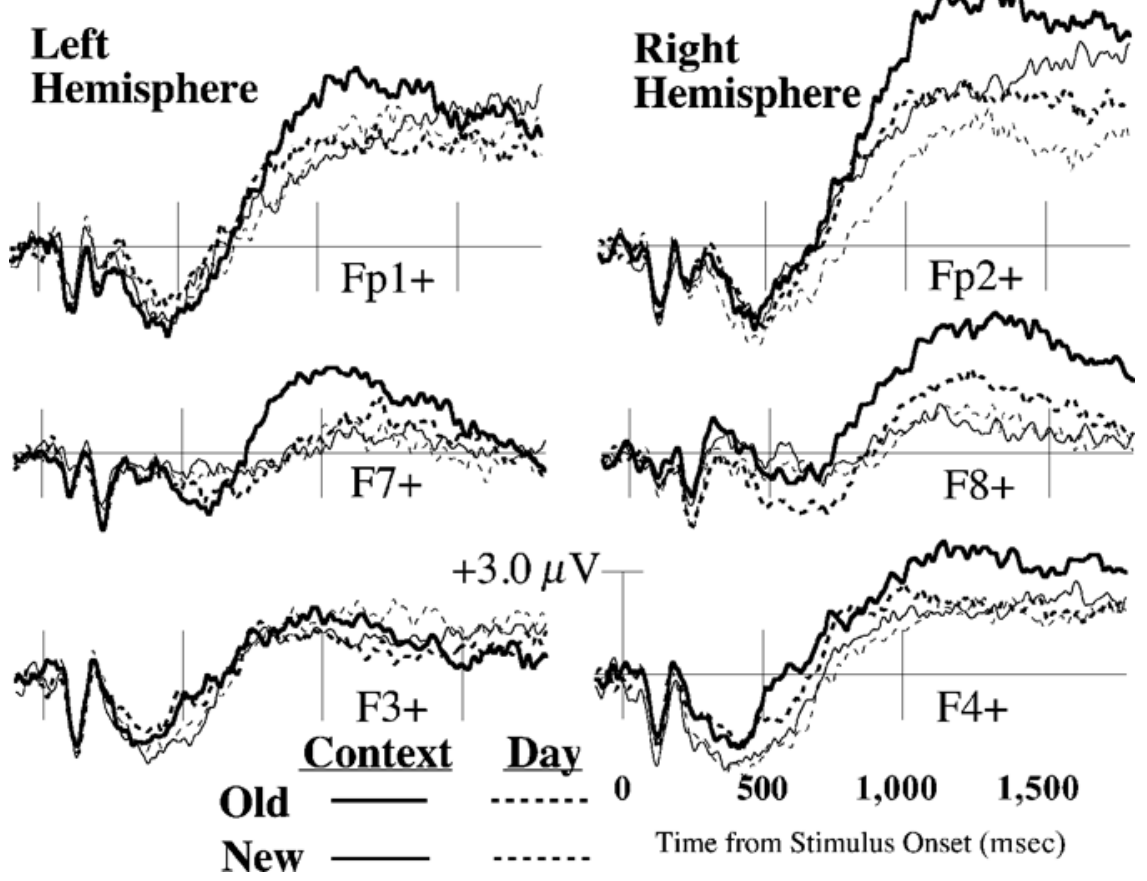

Figure 2. Mean average-referenced event-related brain potentials for each of the four primary conditions. The plotted waveforms were created by averaging channels within each region for each subject and then averaging across all the subjects. See Figure 1 for locations of the $\mathrm{Fp1}+/ \mathrm{Fp} 2+, \mathrm{F} 7+/ \mathrm{F8}+$, and $\mathrm{F3}+/ \mathrm{F} 4+$ regions.

measures. Furthermore, these behavioral results support our contention that ERP differences between tasks are related to the use of location-based (vs. distance-based) processes in reconstructing memory for when an event occurred.

ERP analyses focused on late frontal effects that are likely to index the reconstructive memory processes. Late (800-1,800 msec) frontal ERPs were more positive during the context test than during the day test. Late frontal ERP old/new effects are often attributed to postretrieval evaluation processes (Allan et al., 1998; Curran et al., 2001; Johnson et al., 1996; Ranganath \& Paller, 2000; Wilding, 1999; Wilding \& Rugg, 1997a, 1997b). Such evaluation may be an important aspect of reconstructive memory for the times of past events. However, it is notable that in addition to task differences observed for old items, smaller but significant task differences were observed also for new items. Assuming that little information is retrieved about new items because they were not previously seen, the present frontal effects may reflect something other than postretrieval evaluation processes. For example, these effects may represent differences in retrieval effort or retrieval orientation/mode that would apply to reconstructive processing of both old and new items (e.g., Rugg $\&$ Wilding, 2000). Future research is needed to better specify the aspects of reconstructive processing that are captured by these frontal ERP effects.

The present experiments build upon previous ERP and neuropsychological studies of memory for source/time but go a step further in establishing a relation to the theoretical distinction between location- and distance-based processing. These results can be added to those of many other ERP experiments showing late frontal ERP old/new effects in source memory tasks (Donaldson \& Rugg, 1998; Johnson et al., 1996; Senkfor \& Van Petten, 1998; Tendolkar \& Rugg, 1998; Trott et al., 1999; Van Petten et al., 2000; Wilding, 1999; Wilding \& Rugg, 1996, 1997b). The presence of source-memory-related frontal activity is also consistent with the well-documented source memory deficits observed in patients with frontal lobe injuries (McAndrews \& Milner, 1991; Milner et al., 1991; Moscovitch, 1995; Shimamura et al., 1990; Wheeler et al., 1997). Much of this previous research has shown that frontal mechanisms are more critical for source/time memory than for item memory (e.g., old/new recognition judgments). To our knowledge, the present study is the first to examine memory for time under conditions that varied the utility of reconstructive processing. The results show that a requirement to retrieve temporal information per se is not sufficient to fully engage frontal memory mechanisms. Rather, the frontal contribution to memory for time is specifically related to the use of reconstructive memory processes.

The present research is also relevant to questions regarding the relation between memory for time of occurrence and general notions about the recollection of details from previous experience. Hintzman (2001) directly explored the relation between the subjective experience of 


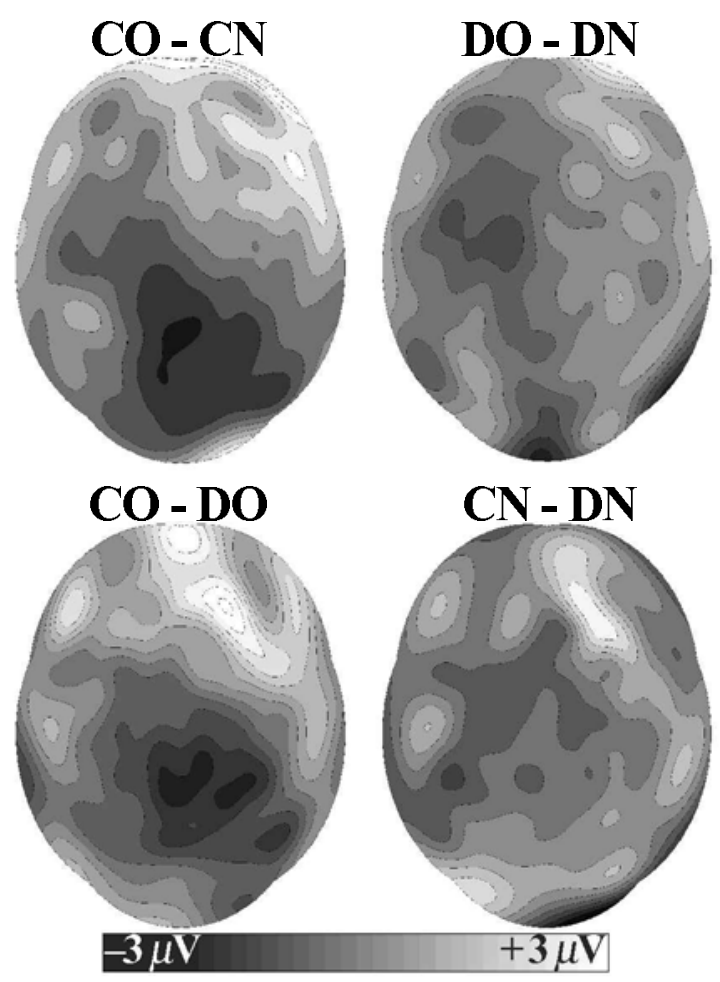

Figure 3. The complete topographies of the main effects. Each oval shows the mean difference between the labeled conditions from 800 to $1,800 \mathrm{msec}$, interpolated over the scalp (nose is on top, left ear on left, etc.). Contour lines are plotted every $0.6 \mu \mathrm{V}$. CO, context/old; CN, context/new; DO, day/old; DN, day/new.

recollection (as estimated by the remember/know procedure) and judgments of recency in a continuous recency discrimination paradigm. He concluded that the results could not be explained completely by either a model in which recollection is necessary for recency judgments or a strength-based signal detection model. Such interpretative ambiguities may arise if behavioral performance reflects a mixture of location- and distance-based processes. The present experiment successfully separated these components by manipulating their relevance to performance and using ERPs to probe the underlying processes. The correlation between late frontal ERP effects and source memory has generally inspired the idea that frontal effects are related to the recollection of details about a previous experience (Allan et al., 1998; Curran et al., 2001). Assuming that late frontal ERP effects are indeed related to recollection, our results suggest that the recollective aspect of memory for time depends on context reconstruction but that recollection of contextual details may not always be necessary for placing events in time. Thus, when list discrimination ability is used as a measure of recollection (e.g., Buchner et al., 1997; Jacoby, 1991; Mulligan \& Hirshman, 1997; Steffens et al., 2000; Yu \& Bellezza, 2000), it would be advisable to arrange conditions so that they foster reconstructive over strength-based discrimination between lists.
Our understanding of past and future research on memory for time may benefit from an appreciation of the distinction between location- and distance-based processing. For example, Fabiani and D. Friedman (1997) explored the relation between aging, frontal lobe functioning, and memory for temporal order. Older subjects' performance on the Wisconsin Card Sorting test (commonly thought to tap frontal lobe functioning) correlated with recency judgments for pictures, but not for words. Fabiani and Friedman suggested that recency judgments may be more strength-based for words but more location-based for pictures, so frontal lobe functioning may have correlated better with the more reconstructive version of the recency judgment task. Our results provide more direct evidence that recency judgments are especially dependent on frontal lobe mechanisms when they involve reconstructive processing. Future neuropsychologicaland aging research may benefit from differentiating location- and distancebased processing, as well as from using the experimental methods developed here.

\section{REFERENCES}

Allan, K., Wilding, E. L., \& RUGG, M. D. (1998). Electrophysiological evidence for dissociable processes contributing to recollection. Acta Psychologica, 98, 231-252.

Bertrand, O., Perin, F., \& Pernier, J. (1985). A theoretical justification of the average reference in topographic evoked potential studies. Electroencephalography \& Clinical Neuroscience, 62, 462-464.

Buchner, A, Erdfelder, E., Steffens, M. C., \& Martensen,H. (1997). The nature of memory processes underlying recognition judgments in the process dissociation procedure. Memory \& Cognition, 25, 508-517.

Butters, M. A., Kaszniak, A. W., Glisky, E. L., Eslinger, P. J., \& Schacter, D. L. (1994). Recency discrimination deficits in frontal lobe patients. Neuropsychology, 8, 343-353.

Cabeza, R, Anderson, N. D., Houle, S., Mangels, J. A., \& Nyberg, L. (2000). Age-related differences in neural activity during item and temporal-order memory retrieval: A positron emission tomography study. Journal of Cognitive Neuroscience, 12, 197-206.

Curran, T. (2000). Brain potentials of recollection and familiarity. Memory \& Cognition, 28, 923-938.

Curran, T., \& Friedman, W. J. (in press). ERP old/new effects at different retention intervals in recency discrimination tasks. Cognitive Brain Research.

Curran, T., Schacter, D. L., Johnson, M. K., \& Spinks, R. (2001). Brain potentials reflect behavioral differences in true and false recognition. Journal of Cognitive Neuroscience, 13, 201-216.

Curran, T., Tucker, D. M., Kutas, M., \& Posner, M. I. (1993). Topography of the N400: Brain electrical activity reflecting semantic expectation. Electroencephalography \& Clinical Neurophysiology, 88, 188-209.

Dien, J. (1998). Issues in the application of the average reference: Review, critiques, and recommendations. Behavior Research Methods, Instruments, \& Computers, 30, 34-43.

Donaldson, D. I., \& RUGG, M. D. (1998). Recognition memory for new associations: Electrophysiological evidence for the role of recollection. Neuropsychologia, 36, 377-395.

Fabiani, M., \& Friedman, D. (1997). Dissociations between memory for temporal order and recognition memory in aging. Neuropsychologia, 35, 129-141.

Friedman, D., \& Johnson, R., JR. (2000). Event-related potential (ERP) studies of memory encoding and retrieval: A selective review. Microscopy Research \& Technique, 51, 6-28.

Friedman, W. J. (1993). Memory for the time of past events. Psychological Bulletin, 113, 44-66.

FriedMAN, W. J. (1996). Distance and location processes in memory for 
the times of past events. In D. L. Medin (Ed.), The psychology oflearning and motivation (Vol. 35, pp. 1-41). San Diego: Academic Press.

Friedman, W. J. (2001). Memory processes underlying humans' chronological sense of the past. In C. Hoerl \& T. McCormack (Eds.), Time and memory: Issues in philosophyand psychology (pp. 139-167). Oxford: Oxford University Press.

Geisser, S., \& Greenhouse, S. W. (1958). An extension of Box's results on the use of the $F$ distribution in multivariate analyses. Annals of Mathematical Statistics, 29, 885-891.

HinTZMAn, D. L. (2001). Judgments of frequency and recency: How they relate to reports of subjective awareness. Journal of Experimental Psychology: Learning, Memory, \& Cognition, 27, 1347-1358.

Hintzman, D. L., \& CurRan, T. (1994). Retrieval dynamics of recognition and frequency judgments: Evidence for separate processes of familiarity and recall. Journal of Memory \& Language, 33, 1-18.

JACOBY, L. L. (1991). A process dissociation framework: Separating automatic from intentional uses of memory. Journal of Memory \& Language, 30, 513-541.

JASPER, H. A. (1958). The ten-twenty system of the international federation. Electroencepholography\& Clinical Neurophysiology, 10, 371-375.

Johnson, M. K., Hashtroudi, S., \& Lindsay, D. S. (1993). Source monitoring. Psychological Bulletin, 114, 3-28.

Johnson, M. K., Kounios, J., \& Nolde, S. F. (1996). Electrophysiological brain activity and memory source monitoring. NeuroReport, $\mathbf{7}$, 2929-2932.

Lehman, D., \& Skrandies, W. (1985). Spatial analysis of evoked potentials in man: A review. Progress in Neurobiology, 23, 227-250.

MANDler, G. (1980). Recognizing: The judgment of previous occurrence. Psychological Review, 87, 252-271.

Mangels, J. A., Gershberg, F. B., Shimamura, A. P., \& Knight, R. T. (1996). Impaired retrieval from remote memory in patients with frontal lobe damage. Neuropsychology, 10, 32-41.

McAndrews, M. P., \& Milner, B. (1991). The frontal cortex and memory for temporal order. Neuropsychologia, 29, 849-859.

Mecklinger, A. (2000). Interfacing mind and brain: A neurocognitive model of recognition memory. Psychophysiology, 37, 565-582.

Milner, B., Corsi, P., \& Leonard, G. (1991). Frontal-lobe contribution to recency judgments. Neuropsychologia, 29, 601-618.

Moscovitch, M. (1995). Models of consciousness and memory. In M. S. Gazzaniga (Ed.), The cognitive neurosciences (pp. 1341-1356). Cambridge, MA: MIT Press.

Moscovitch, M., \& Melo, B. (1997). Strategic retrieval and the frontal lobes: Evidence from confabulation and amnesia. Neuropsychologia, 35, 1017-1034.

Mulligan, N. W., \& Hirshman, E. (1997). Measuring the bases of recognition memory: An investigation of the process dissociation framework. Journal of Experimental Psychology: Learning, Memory, \& Cognition, 23, 280-304.

Picton, T. W., Lins, O. G., \& Scherg, M. (1995). The recording and analysis of event-related potentials. In F. Boller \& J. Grafman (Eds.), Handbook of neuropsychology (Vol. 10, pp. 3-73). Amsterdam: Elsevier.

Ranganath, C., \& Paller, K. A. (2000). Neural correlates of memory retrieval and evaluation. Cognitive Brain Research, 9, 209-222.

RugG, M. D., \& WiLdING, E. L. (2000). Retrieval processing and episodic memory. Trends in the Cognitive Sciences, 4, 108-115.

Senkfor, A. J., \& Van Petten, C. (1998). Who said what? An eventrelated potential investigation of source and item memory. Journal of Experimental Psychology: Learning, Memory, \& Cognition, 24, 1005-1025.

Shimamura, A. P., Janowsky, J. S., \& Seuire, L. R. (1990). Memory for the temporal order or events in patients with frontal lobe lesions and amnesic patients. Neuropsychologia, 28, 803-813.

SNOdGRAss, J. G., \& VANDERWART, M. (1980). A standardized set of 260 pictures: Norms for name agreement, image agreement, familiarity, and visual complexity. Journal of Experimental Psychology: Human Learning \& Memory, 6, 174-215.

Srinivasan, R., Nunez, P. L., Silberstein, R. B., Tucker, D. M., \& CADUsch, P. J. (1996). Spatial sampling and filtering of EEG with spline-Laplacians to estimate cortical potentials. Brain Topography, $\mathbf{8}$, 355-366

Steffens, M. C., Buchner, A., Martensen, H., \& Erdfelder, E. (2000). Further evidence on the similarity of memory processes in the process dissociation procedure and in source monitoring. Memory \& Cognition, 28, 1152-1164.

Tendolkar, I., \& RUGg, M. D. (1998). Electrophysiologicaldissociation of recency and recognition memory. Neuropsychologia, 36, 477-490.

Trott, C. T., Friedman, D., Ritter, W., Fabiani, M., \& Snodgrass, J. G. (1999). Episodic priming and memory for temporal source: Eventrelated potentials reveal age-related differences in prefrontal functioning. Psychology \& Aging, 14, 390-413.

Tucker, D. M. (1993). Spatial sampling of head electrical fields: The geodesic sensor net. Electroencephalography \& Clinical Neurophysiology, 87, 154-163.

Tucker, D. M., Liotti, M., Potts, G. F., Russell, G. S., \& Posner, M. I. (1994). Spatiotemporal analysis of brain electrical fields. Human Brain Mapping, 1, 134-152.

Van Petten, C., Senkfor, A. J., \& Newberg, W. M. (2000). Memory for drawings in locations: Spatial source memory and event-related potentials. Psychophysiology, 37, 551-564.

Wheeler, M. A., Stuss, D. T., \& Tulving, E. (1997). Toward a theory of episodic memory: The frontal lobes and autonoetic consciousness. Psychological Bulletin, 121, 331-354.

WILDING, E. L. (1999). Separating retrieval strategies from retrieval success: An event-related potential study of source memory. Neuropsychologia, 37, 441-454.

WiLDING, E. L., \& RUGG, M. D. (1996). An event-related potential study of recognition memory with and without retrieval of source. Brain, 119, 889-905.

Wilding, E. L., \& RugG, M. D. (1997a). Event-related potential and the recognition memory exclusion task. Neuropsychologia, 35, 119-128.

Wilding, E. L., \& RugG, M. D. (1997b). An event-related potential study of recognition memory for words spoken aloud or heard. Neuropsychologia, 35, 1185-1195.

Yu, J., \& Bellezza, F. S. (2000). Process dissociation as source monitoring. Journal of Experimental Psychology: Learning, Memory, \& Cognition, 26, 1518-1533.

Zorrilla, L. T., Aguirre, G. K., Zarahn, E., Cannon, T. D., \& D'EsPosito, M. (1996). Activation of the prefrontal cortex during judgments of recency: A functional MRI study. NeuroReport, 7, 2803-2806.

\section{NOTES}

1. No behavioral or late frontal ERP differences were obtained when the results from the two studied lists were compared within each test type (i.e., day test, List 1 vs. List 2; context test, List 2 vs. List 3).

2 . Twelve subjects had insufficient numbers of artifact-free trials because of low accuracy in one or more conditions. Six subjects had excessive eye movements.

\section{APPENDIX Memory-Strategies Questionnaire}

1. Memory for the day of the week I saw a picture.

2. I judged when a picture had occurred by remembering what sort of judgment I had made about it.

3. I just guessed in which set a picture had been presented.

4. Clarity of my memory for a picture.

5. I remembered some of my thoughts about a picture when I studied it.

6 . Whether a picture seemed to have occurred early or late among those pictures presented on a given day.

7. Vividness of my memory for a picture.

8. Memory for the approximate clock time when I saw a picture.

9. The strength of my memory for a picture.

10. I remembered the type of judgments I made for pictures that were studied nearby in the same list.

(Manuscript received November 30, 2001; revision accepted for publication May 31, 2002.) 